\title{
$\gamma$-Aminobutyric acid immunostaining in the antennal lobe of the moth Heliothis virescens and its colocalization with neuropeptides
}

\author{
Bente G. Berg • Joachim Schachtner • Uwe Homberg
}

Received: 26 September 2008 / Accepted: 12 December 2008 / Published online: 21 January 2009

(C) The Author(s) 2009. This article is published with open access at Springerlink.com

\begin{abstract}
The antennal lobe is the primary processing center for olfactory information in insects. To understand further the neural circuitry of this brain area, we have investigated the distribution of $\gamma$-aminobutyric acid (GABA) and its colocalization with neuropeptides in the antennal lobe of the noctuid moth Heliothis virescens. Immunocytochemical experiments with an antiserum against GABA showed a large number of labeled somata in the antennal lobe; these somata were located exclusively in the lateral cell cluster. Stained neurites innervating all antennal-lobe glomeruli, including the male-specific macroglomerular complex, suggested a prominent role of GABA in processing olfactory information, including signals from pheromones, interspecifically acting odors, and plant odors. Fibers in two antennocerebral tracts (the middle and dorsal antennocerebral tract) exhibited prominent GABA immunoreactivity. Double-labeling experiments revealed that immunostaining for three neuropeptides, viz., A-type allatostatin, Manduca sexta allatotropin, and FMRFamide-related peptides, was largely colocalized with GABA in cell bodies of the lateral cell cluster. The general absence of peptide immunostaining in the antennocerebral tracts strongly indicated that these peptides were colocalized with GABA in local interneurons of the antennal lobe. In contrast, tachykinin-related peptides
\end{abstract}

This work was supported by the Norwegian University of Science and Technology (project no. 80902101).

\footnotetext{
B. G. Berg $(\bowtie)$

Neuroscience Unit/Department of Psychology,

Norwegian University of Science and Technology,

7489 Trondheim, Norway

e-mail: Bente.Berg@ntnu.no

J. Schachtner $\cdot$ U. Homberg

Department of Biology, Animal Physiology, Philipps University,

35032 Marburg, Germany
}

occurred in a distinct population of local antennal-lobe neurons that did not exhibit GABA immunostaining. Thus, local interneurons that were not GABAergic were present in the moth antennal lobe.

Keywords GABA immunocytochemistry - Antennal lobe . Olfactory system - GABA/neuropeptide colocalization . Heliothis virescens (Insecta)

\section{Introduction}

Odor molecules are detected by a large repertoire of olfactory receptor neurons that project to the primary olfactory center of the brain, viz., the antennal lobe in insects, and the olfactory bulb in mammals (Hildebrand and Sheperd 1997). In both groups, this first-order synaptic neuropil is characterized by an array of spherical structures termed olfactory glomeruli (Shepherd 1974; Anton and Homberg 1999). The connection of plentiful detectors directly linked to a certain number of glomeruli is obviously a favorable organization for encoding olfactory information. The logic of this projection pattern is demonstrated in the noctuid moth Heliothis virescens in which four male-specific receptor neuron types carry olfactory information from the external world to specific addresses in the brain, i.e., the four subunits of the macroglomerular complex (MGC; Hansson et al. 1995; Berg et al. 1998). The ligands of the male-specific receptors include pheromone substances produced by conspecific females and substances produced by females of related species. The two categories of signal information (intraspecific and interspecific) are mediated along separate pathways and induce two opposite behavioral responses: attraction versus repulsion (Almaas and Mustaparta 1991; 
Berg et al. 1995; 1998; Christensen et al. 1995; Hansson et al. 1995; Vickers et al. 1998; Vickers and Christensen 2003). The ordinary glomeruli, which are targets of plant odor sensory neurons, are present in both males and females (Stranden et al. 2003; Rø et al. 2006). In $H$. virescens, the total number of antennal-lobe glomeruli, including dimorphic and isomorphic units, comprises 64 in the male and 62 in the female (Berg et al. 2002).

In general, the antennal-lobe glomeruli are innervated by three categories of central interneurons: projection neurons that link the antennal lobe to the protocerebrum, local interneurons that are multiglomerular anaxonal elements residing within the antennal lobe, and centrifugal neurons that send axonal projections into the antennal lobe (Homberg et al. 1989). Projection neurons convey olfactory information from the antennal lobe to two main areas in the protocerebrum: the calyces of the mushroom bodies and the lateral protocerebrum. Their axons form three main pathways termed the inner, the middle, and the outer antenno-cerebral tract (Homberg et al. 1988; Rø et al. 2006). The cell bodies of projection and local interneurons are gathered into three cell groups covering the glomerular neuropil: a prominent ventro-lateral, a smaller medial, and a tiny anterior cell cluster (Homberg et al. 1989). Centrifugal neurons usually have their cell bodies located in the protocerebrum or subesophageal ganglion (for a review, see Schachtner et al. 2005).

$\gamma$-Aminobutyric acid (GABA) is the major inhibitory transmitter in the insect brain, and GABAergic synaptic input in the antennal lobe is essential for olfactory processing (for reviews, see Boeckh and Tolbert 1993; Laurent 2002). In all species studied so far, GABA is abundantly present in local interneurons of the antennal lobe, as demonstrated by immunostaining (Manduca sexta: Hoskins et al. 1986; Apis mellifera: Schäfer and Bicker 1986; Periplaneta americana: Distler 1989; Schistocerca gregaria: Leitch and Laurent 1996). Physiological studies in $M$. sexta have indicated that GABA is responsible for amplifying contrasts via interglomerular interactions (Lei et al. 2002). More precisely, GABA is believed to induce odor-released synchronization of projection neuron activity in the antennal lobe in such a way that the differences between odor signals are enhanced. Synchronization of firing patterns in groups of antennal-lobe projection neurons was demonstrated for the first time in locusts (MacLeod and Laurent 1996). Studies of vertebrates (for a review, see Möhler 2006) and invertebrates (Wilson and Laurent 2005) have led to the common acceptance that GABA influences the timing of spiking activity and consequently plays a decisive role in creating network oscillations.

As in other neural networks, many other neurotransmitter candidates have been identified in the antennal lobe. These include acetylcholine, serotonin, dopamine, octop- amine, histamine, and various neuropeptides (Homberg and Müller 1999; Schachtner et al. 2005; Shang et al. 2007). In general, all nervous systems show the coexistence of peptides and small molecule transmitters within the same neuron (for a review, see Salio et al. 2006). Recently, we have investigated the distribution of neuropeptides in the central olfactory pathway of $H$. virescens (Berg et al. 2007). Immunocytochemistry and MALDI-TOF mass spectrometry have provided evidence for the presence of members of four neuropeptide families, viz., allatostatins (AST-As), Manduca sexta allatotropin (Mas-AT), FMRFamide-related peptides (FaRPs), and tachykinin-related peptides (TKRPs), in the antennal lobe. The various antisera label mainly local interneurons and show distinct staining patterns. Particularly noticeable is the distribution of TKRP immunostaining, which differs considerably from that of the other neuropeptides. Double-label experiments have revealed the colocalization of Ast-As, Mas-ATs, and FaRPs, whereas TKRP immunoreactivity occurs in distinct neurons.

To investigate further the distribution of neuroactive substances in the central olfactory pathway, we have studied the distribution of GABA in the antennal lobe of $H$. virescens by immunostaining. We demonstrate GABA immunoreactivity in a large number of local neurons and in two antennocerebral tracts. Double-labeling experiments have shown that AST-As, Mas-AT, and FaRPs are present in subpopulations of GABA-immunoreactive local neurons but has revealed no colocalization between GABA and TKRP immunolabeling. This demonstrates the presence of local interneurons that are not GABAergic in the antennal lobe of the moth.

\section{Materials and methods}

Insects

H. virescens (Lepidoptera: Noctuidae) pupae, originating from a laboratory culture, were kindly provided by Syngenta, Basel, Switzerland. Male and female pupae were kept on a phase-shifted light/darkness photoperiod of $14 \mathrm{~h}: 10 \mathrm{~h}$ at $25^{\circ} \mathrm{C}$. The animals were allowed to feed on sugar-water. All experiments were performed on adults, 15 days after ecdysis. No differences in immunostaining were observed between isomorphic brain structures of males and females.

\section{Antisera}

For the immunostaining of $H$. virescens brain sections, we used a rabbit antiserum raised against conjugates of GABA covalently coupled to keyhole limpet hemocyanin (KLH; Table 1; generously provided by Dr. T.G. Kingan, US 
Department of Agriculture, Beltsville, Md., USA). In specificity tests on brain sections of $H$. virescens, the GABA antiserum $(1: 3,000)$ was preincubated prior to its application to the sections with four different concentrations $(10 \mathrm{nM}, 100 \mathrm{nM}, 1 \mu \mathrm{M}, 10 \mu \mathrm{M})$ of GABA conjugated to KLH (12 mg/8 ml; Sigma-Aldrich) by glutaraldehyde. Preadsorption of the antiserum with GABA-glutaraldehyde$\mathrm{KLH}$ at $10 \mathrm{nM}$ reduced the staining intensity, whereas higher concentrations of the antigen abolished all immunostaining (data not shown).

For double-labeling experiments, antisera, also raised in rabbit, against the following neuropeptides were utilized: Diploptera allatostatin 7 (Dip-Ast7), M. sexta allatotropin (Mas-AT), the tetrapeptide FMRFamide, and locustatachykinin II (LomTK II; for further details, see Table 1 and Berg et al. 2007). The antisera against Dip-Ast7 and LomTK II were generously provided by Dr. Hans Agricola (University of Jena, Germany), whereas antisera against Mas-AT and FMRFamide were gifts from Dr. Jan Veenstra (University of Bordeaux, Talence, France; Veenstra and Hagedorn 1993) and Dr. Eve Marder (Brandeis University, USA), respectively. The specificities of the four neuropeptide antisera in $H$. virescens nervous tissue were as previously tested by liquidphase preadsorption (Berg et al. 2007). For labeling of neuropil structures including olfactory glomeruli, a monoclonal mouse antibody against Drosophila synaptic-vesicleassociated protein synapsin I, kindly provided by Dr. E. Buchner (University of Würzburg, Germany) was used.

Immunocytochemistry

GABA immunostaining was performed on mounted paraffin sections and free-floating vibratome sections by the indirect peroxidase-antiperoxidase (PAP) technique (Sternberger 1979). After the animals had been anesthetized by cooling, brains were dissected from the head capsule in cold saline (Weevers 1966) and fixed in 1 part 25\% glutaralaldehyde/3 parts saturated picric acid $/ 1 \%$ acetic acid (GPA; Boer et al. 1979) overnight at $4^{\circ} \mathrm{C}$ or for $1-2 \mathrm{~h}$ at room temperature. Brains intended for paraffin sectioning were dehydrated through a series of ethanols and toluene before being embedded in Paraplast Plus (Sigma, Steinheim, Germany). A rotary microtome was used to cut 8 - $\mu$ m-thick sections from frontally or dorsally positioned preparations. The sections were dried on microscope slides at room temperature for at least $4 \mathrm{~h}$ before being deparaffinized in xylene and ethanols and finally hydrated. To minimize non-specific staining, the sections were preincubated for $1 \mathrm{~h}$ in TRISbuffered saline (TBS; $0.3 \mathrm{M} \mathrm{NaCl} / 0.1 \mathrm{M}$ TRIS-HCl, $\mathrm{pH}$ 7.4) containing $0.5 \%$ Triton $\mathrm{X}-100(\operatorname{TrX})$ and $5 \%$ normal goat serum (NGS). The GABA antiserum was diluted 1:2000 in TBS containing $0.5 \% \operatorname{TrX}$ and $1 \%$ NGS. The incubation time was $20 \mathrm{~h}$ at room temperature. As a secondary antibody, goat-anti-rabbit IgG (Sigma) was applied at 1:40 for $1 \mathrm{~h}$, and then rabbit PAP at 1:300 for $1 \mathrm{~h}$. Staining was visualized by means of a solution of 3,3'-diaminobenzidine tetrahydrochloride (DAB) containing $5 \mathrm{mg} \mathrm{DAB} / 15 \mathrm{ml} 0.1 \mathrm{M}$ phosphate buffer ( $\mathrm{pH}$ 7.4) and $0.015 \% \mathrm{H}_{2} \mathrm{O}_{2}$. Between the various steps of the protocol, the sections were rinsed in TBS containing $0.1 \% \operatorname{TrX}$. The sections were dehydrated, cleared in xylene, and embedded in Entellan (Merck) under glass coverslips.

Brains prepared for free-floating vibratome sections were treated as described by Berg et al. (2007). After fixation, the preparations were embedded in a frontal or dorsal orientation in gelatin/albumin, postfixed overnight in $4 \%$ buffered

Table 1 Antisera used

\begin{tabular}{|c|c|c|c|c|c|}
\hline Antiserum & Antigen & $\begin{array}{l}\text { Source and first } \\
\text { characterization }\end{array}$ & $\begin{array}{l}\text { Specificity tests in } \\
\text { H. virescens }\end{array}$ & $\begin{array}{l}\text { Working dilution for } \\
\text { PAP-technique }\end{array}$ & $\begin{array}{l}\text { Working dilution for } \\
\text { immunofluorescence }\end{array}$ \\
\hline Anti-GABA (9/24) & $\begin{array}{l}\text { GABA-keyhole } \\
\text { limpet } \\
\text { hemocyanin }\end{array}$ & $\begin{array}{l}\text { T.G. Kingan } \\
\text { (Hoskins } \\
\text { et al. 1986) }\end{array}$ & This study & $\begin{array}{l}\text { Paraffin sections, 1:2,000; } \\
\text { vibratome sections; 1:3,000 }\end{array}$ & $1: 2,000$ \\
\hline $\begin{array}{l}\text { Anti-Diploptera } \\
\text { allatostatin } 7\end{array}$ & $\begin{array}{l}\text { Allatostatin 7- } \\
\text { thyroglobulin }\end{array}$ & $\begin{array}{l}\text { H. Agricola } \\
\text { (Vitzthum } \\
\text { et al. 1996) }\end{array}$ & Berg et al. 2007 & - & $1: 50,000$ \\
\hline $\begin{array}{l}\text { Anti-Manduca (Mas-AT) } \\
\text { allatotropin (13.3.91) }\end{array}$ & $\begin{array}{l}\text { Mas-AT } \\
\text { thyroglobulin }\end{array}$ & $\begin{array}{l}\text { J. Veenstra } \\
\text { (Veenstra } \\
\text { and Hagedorn } \\
\text { 1993) }\end{array}$ & & & $1: 15,000$ \\
\hline Anti-FMRFamide $(671 \mathrm{~N})$ & $\begin{array}{l}\text { FMRFa- } \\
\text { thyroglobulin }\end{array}$ & $\begin{array}{l}\text { E. Marder } \\
\text { (Marder } \\
\text { et al. 1987) }\end{array}$ & & & $1: 5,000$ \\
\hline $\begin{array}{l}\text { Anti-locustatachykinin II (Lom- } \\
\text { TK II; K1-50820091) }\end{array}$ & $\begin{array}{l}\text { Lom-TK II } \\
\text { thyroglobulin }\end{array}$ & $\begin{array}{l}\text { H. Agricola } \\
\text { (Nässel } \\
\text { et al. 1995) }\end{array}$ & & & $1: 10,000$ \\
\hline
\end{tabular}


formaldehyde, and sectioned at $30 \mu \mathrm{m}$ with a vibrating blade microtome (Leica VT 1000 S; Nussloch, Germany). In these experiments, the GABA antiserum was applied at $1: 3,000$. Finally, the sections were mounted on chrome alum/gelatin-coated glass slides, dehydrated, cleared in xylene, and embedded in Entellan under glass coverslips.

\section{Double-labeling experiments}

To investigate the colocalization of GABA and neuropeptides in the antennal lobe of $H$. virescens, the antiserum against GABA was applied in combination with each of the four neuropeptide antisera in double-labeling experiments. Experiments were performed on vibratome sections. Brains were fixed in a mixture consisting of $0.5 \mathrm{ml}$ formaldehyde,

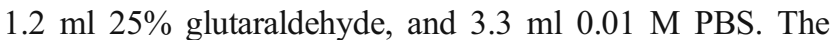
fixed brains were embedded and sectioned with the vibratome as described above. To minimize background fluorescence, the free-floating sections were treated with $1 \%$ sodium borohydride solution (100 mg sodium borohydride, $10 \mathrm{ml} 0.1 \mathrm{M}$ phosphate buffer, $\mathrm{pH} 7.4$ ) containing $10 \% \operatorname{TrX}$. After a thorough rinse in TBS containing $1 \% \operatorname{TrX}$, the sections were further processed according to a method modified from that of Negoescu et al. (1994) for doubleimmunolabeling with primary antisera from the same species. The brain sections were preincubated in TBS containing $0.5 \% \operatorname{TrX}$ and 5\% normal donkey serum (NDS) for $1 \mathrm{~h}$ at room temperature. The primary antibodies were diluted in TBS containing $0.5 \% \operatorname{TrX}$ and $1 \%$ NDS at the following concentrations: anti-GABA, 1:2,000; anti-DipAst7, 1:50,000; anti-Mas-AT, 1:15,000; anti-FMRFamide, 1:5,000; anti-LomTK II, 1:10,000. Since all antibodies were raised in rabbit, they had to be applied in consecutive steps. The neuropeptide antiserum was used in the first staining cycle and anti-GABA in the second. Incubation in the neuropeptide antiserum lasted $20 \mathrm{~h}$ at room temperature. To block binding sites for the primary antiserum in the second staining cycle, monovalent $\mathrm{Fab}$ fragments (goat-anti-rabbit; Jackson ImmunoResearch, Westgrove, Pa.) diluted in TBS$0.5 \% \operatorname{TrX}$ buffer, including $1 \% \mathrm{NDS}$, were then applied at a concentration of $1: 40$ to the preparations for $2 \mathrm{~h}$ at room temperature. The sections were subsequently washed and incubated for $1 \mathrm{~h}$ with a Cy3-conjugated donkey-anti-goat antiserum (Jackson ImmunoResearch, diluted 1:300). From this stage onward, the preparations were treated in darkness. In the second staining cycle, the sections were preincubated in TBS, containing 5\% NDS, for $30 \mathrm{~min}$, followed by incubation with the second primary antiserum, viz., antiGABA, for 2 days at room temperature. To reduce background staining, $2 \%$ milk powder was added to the primary antibody in the second cycle. The sections were subsequently washed and incubated with Cy2-conjugated donkey anti-rabbit antibody (Jackson ImmunoResearch) in
TBS containing $0.5 \% \operatorname{TrX}$ and $1 \%$ NDS for $1 \mathrm{~h}$. For the labeling of neuropil structures, the monoclonal anti-synapsin I antibody was applied simultaneously with the anti-GABA antiserum and, likewise, the corresponding secondary antiserum, Cy5-conjugated donkey-anti-mouse (Jackson ImmunoResearch) together with Cy3-conjugated donkey anti-goat. Finally, the sections were thoroughly washed and mounted on chrome alum/gelatin-coated microscope slides as described above.

Image processing and data analysis

The DAB-treated sections were analyzed and photographed via a Zeiss digital camera mounted on a Zeiss bright-field microscope (Axiovision Z1). Images including neuropil structures of the antennal lobes and antennocerebral tracts were imported into Adobe Photoshop 7.0 for adjustments and were finally edited in Adobe Illustrator CS2. The doublelabeled preparations were analyzed by using a confocal laser scanning microscope (Leica TCS SP2) and were treated further as described above. Scans for Cy2-fluorescence $\left(\mathrm{Ex}_{\max }\right.$ $\left.490 \mathrm{~nm}, \mathrm{Em}_{\max } 508 \mathrm{~nm}\right), \mathrm{Cy} 3$-fluorescence $\left(\mathrm{Ex}_{\max } 550 \mathrm{~nm}\right.$, $\left.\mathrm{Em}_{\max } 570 \mathrm{~nm}\right)$, and Cy5-fluorescence $\left(\mathrm{Ex}_{\max } 650 \mathrm{~nm}\right.$, $\mathrm{Em}_{\max } 674 \mathrm{~nm}$ ) were performed with an argon laser at $488 \mathrm{~nm}$, an $\mathrm{He} / \mathrm{Ne}$ laser at $543 \mathrm{~nm}$, and an $\mathrm{He} / \mathrm{Ne}$ laser at $633 \mathrm{~nm}$, respectively, in the sequential scanning mode at $1024 \times 1024$ pixel resolution by using a $20 \times$ or $40 \times$ objective (HC PL APO 20x/0.70 $1 \mathrm{~mm}$ Corr CS and HCX PL APO 40x/1.25-0.75 Oil CS; Leica, Bensheim, Germany). The pinhole size was $1 \mu \mathrm{m}$, and the distance between the optical sections was usually $1 \mu \mathrm{m}$.

The numbers of antennal-lobe neurons immunoreactive for GABA were calculated from the paraffin sections by counting the total number of stained cell bodies in three antennal lobes originating from three individuals. To compensate for cell bodies that were cut and counted twice in adjacent sections, cell counts were corrected according to the relationship derived by Abercrombie (1946). To estimate mean cell body size, the diameter of 145 immunoreactive somata, selected from two antennal lobes, was measured. Positional information is given with respect to the body axis of the insect.

\section{Results}

Immunostaining in antennal lobe

Application of antiserum against GABA resulted in distinct staining of several neuropil areas of the central olfactory pathway (Fig. 1a). These included the antennal-lobe glomeruli, the calyces of the mushroom bodies, and the lateral protocerebrum. In the antennal lobe, each glomeru- 

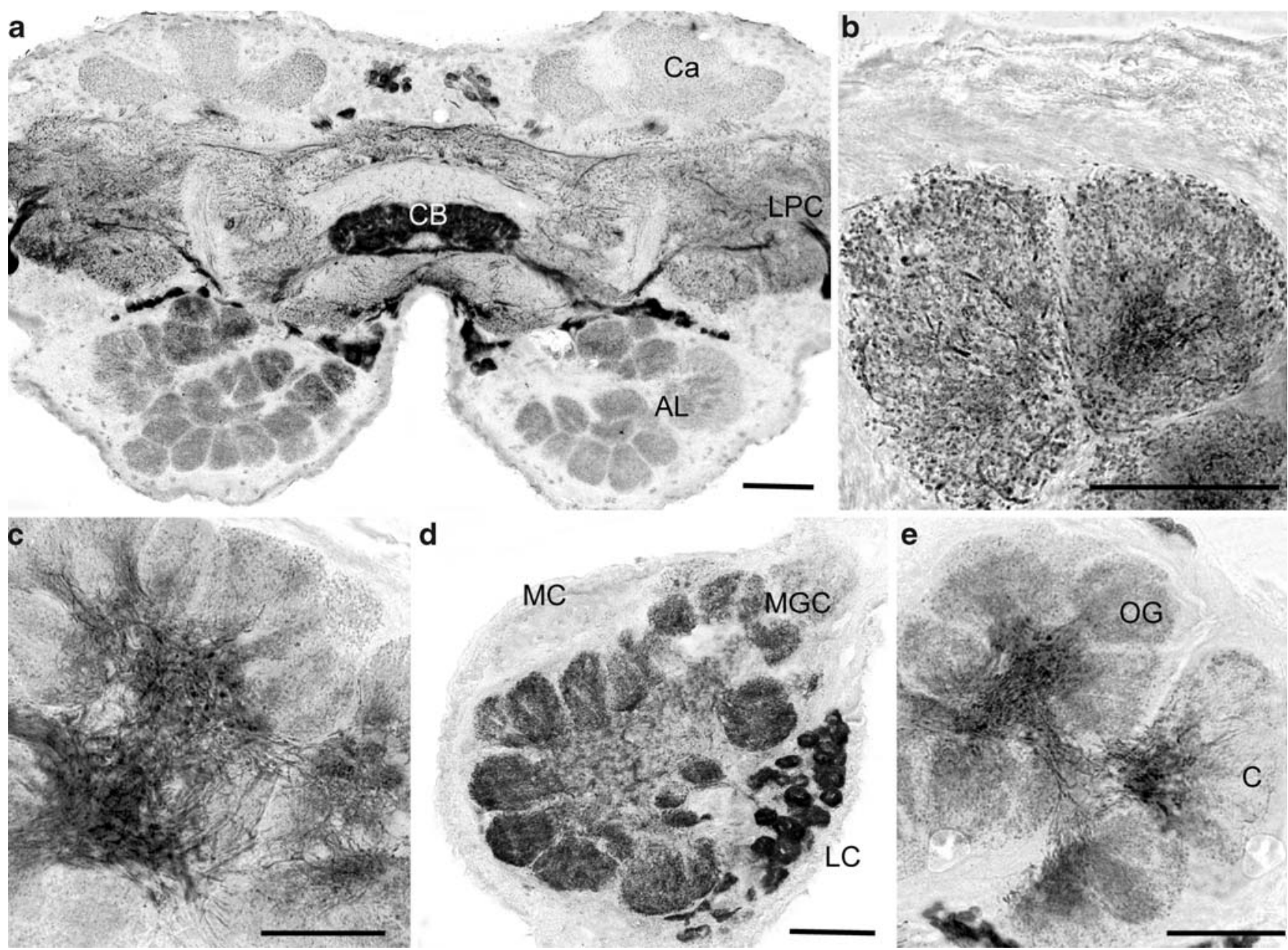

d
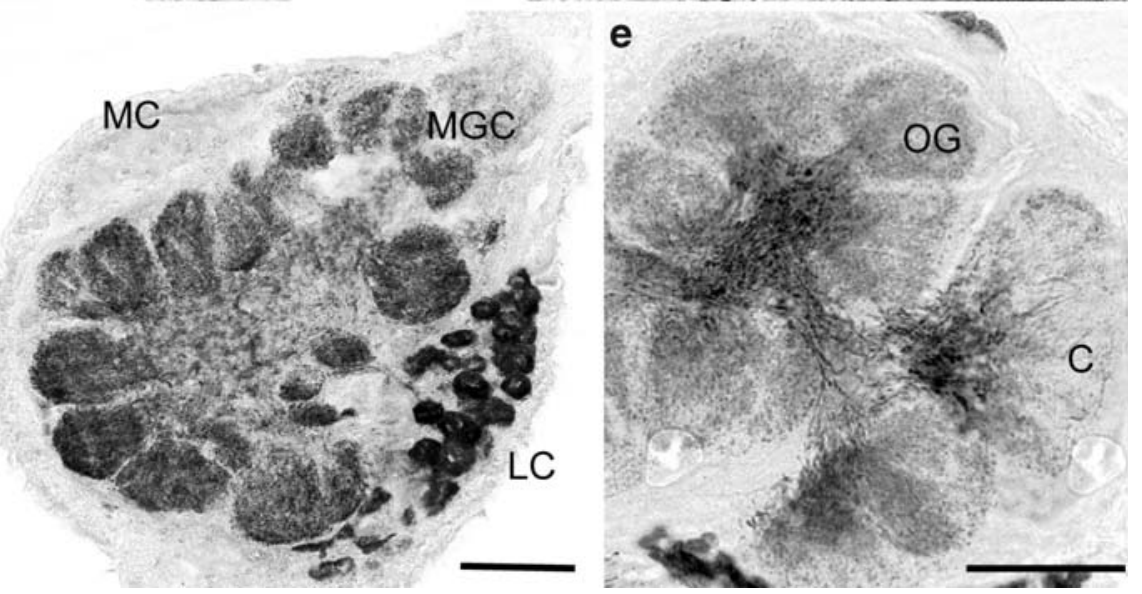

Fig. 1 GABA immunostaining in the brain of Heliothis virescens. a Horizontal section showing immunostaining in most parts of the brain including the antennal lobes $(A L)$, the calyces of the mushroom body $(C a)$, and the lateral protocerebrum $(L P C)$ ( $C B$ central body). b High magnification of a section through the antennal lobe. Glomerular labeling is characterized by a meshwork of fine processes throughout the glomerulus. Staining intensity is higher in the center than in the periphery of the glomeruli. c Part of the antennal lobe showing GABA

immunostaining in the central coarse neuropil. d Frontal section through the antennal lobe (MGC macroglomerular complex). Immunoreactive somata are concentrated in the lateral cell cluster $(L C)$ but are totally lacking in the medial cell cluster $(M C)$. e Horizontal section through a male antennal lobe showing the cumulus $(C)$ of the macroglomerular complex and the array of ordinary glomeruli $(O G)$. The large cumulus is more sparsely invaded by immunoreactive fibers than the ordinary glomeruli. Bars $50 \mu \mathrm{m}$

lus was labeled by a fine network pervading the entire structure (Fig. 1b). Labeling was slightly more intense in the glomerular core than in the periphery. Immunostaining in the central coarse neuropil of the antennal lobe (a structure devoid of glomeruli and mainly containing primary neurites of antennal-lobe neurons) was concentrated in large-diameter fibers (Fig. 1c). In some preparations, the glomeruli located in the posterior-medial part of the antennal lobe were more extensively stained than the others. The somata of the immunoreactive neurons were exclusively located in the lateral cell cluster of the antennal lobe; none were observed in the anterior or the medial cluster (Fig. 1d). In total, $327 \pm 12$ labeled cell bodies with an average diameter of $10.4 \pm 2.6 \mu \mathrm{m}$ were counted in the antennal lobe. The male-specific glomeruli constituting the
MGC could be recognized easily at the antennal nerve entrance (Fig. 1d,e). The large units of the MGC, in particular the cumulus, were more sparsely invaded by immunostained profiles than the ordinary glomeruli (Fig. 1e). No difference in immunostaining in the isomorphic glomeruli was observed between the two sexes.

Immunostaining in antennocerebral tracts

The inner antennocerebral tract projecting from the antennal lobe to the calyces of the mushroom body appeared as a thick bundle of unstained axons, except for two immunoreactive fibers (Fig. 2a). Their target projections in the protocerebrum could not be traced. In contrast to the immunonegative inner antennocerebral tract, the middle 
antennocerebral tract (MACT) projecting to the lateral protocerebrum contained a considerable number of labeled axons (Fig. 2b). In the protocerebrum, the stained fiber bundle divided and targeted two different areas (Figs. 2b, 3a). The outer antennocerebral tract targeting the lateral protocerebrum via a more ventrally located pathway (Fig. 3c) also included some GABA-immunolabeled neurons, visible as they left the antennal lobe (Fig. 2c). In addition to the three main antennocerebral pathways, the dorsal antennocerebral tract running more dorsally appeared as a tight bundle of strongly labeled axons (Figs. 2d-f, 3b). In addition to the protocerebral pathways, a few stained fibers connected the antennal lobe with the antennal mechanosensory and motor center and/or the subesophageal ganglion (Fig. 2g).

\section{Double-labeling experiments}

The distribution of GABA immunostaining was compared with labeling for AST-As, Mas-AT, FaRPs, and TKRPs by
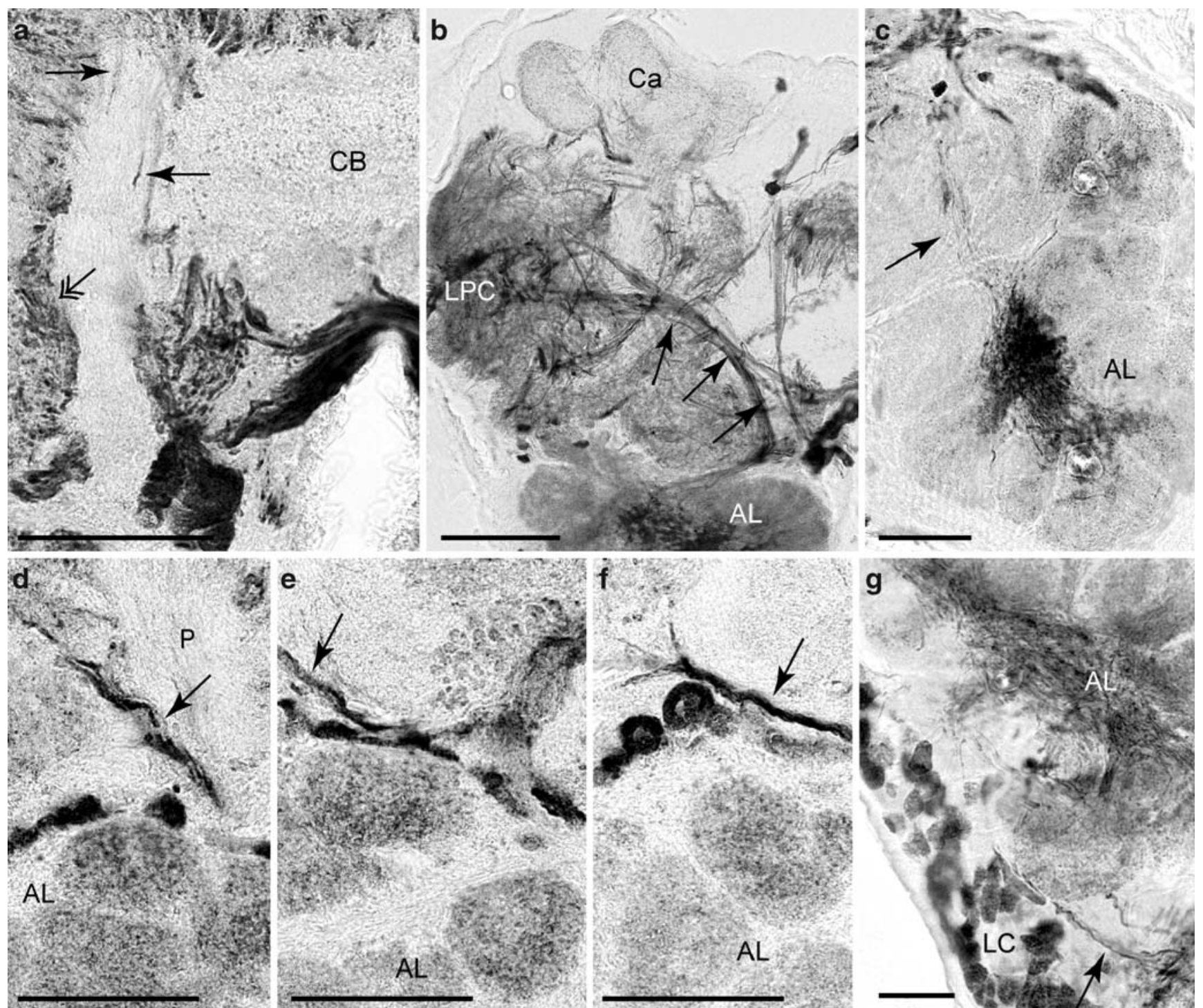

Fig. 2 GABA immunoreactivity in the antennocerebral tracts of the moth brain. a Horizontal section showing lack of immunostaining in the inner antennocerebral tract. Only two stained axons (arrows) can be seen as they pass the central body $(C B)$. Note part of the middle antennocerebral tract (double arrow). b Fibers in the middle antennocerebral tract (arrows), which projects directly from the antennal lobe $(A L)$ to the lateral protocerebrum $(L P C)$, show prominent GABA immunostaining ( $\mathrm{Ca}$ calyces of the mushroom
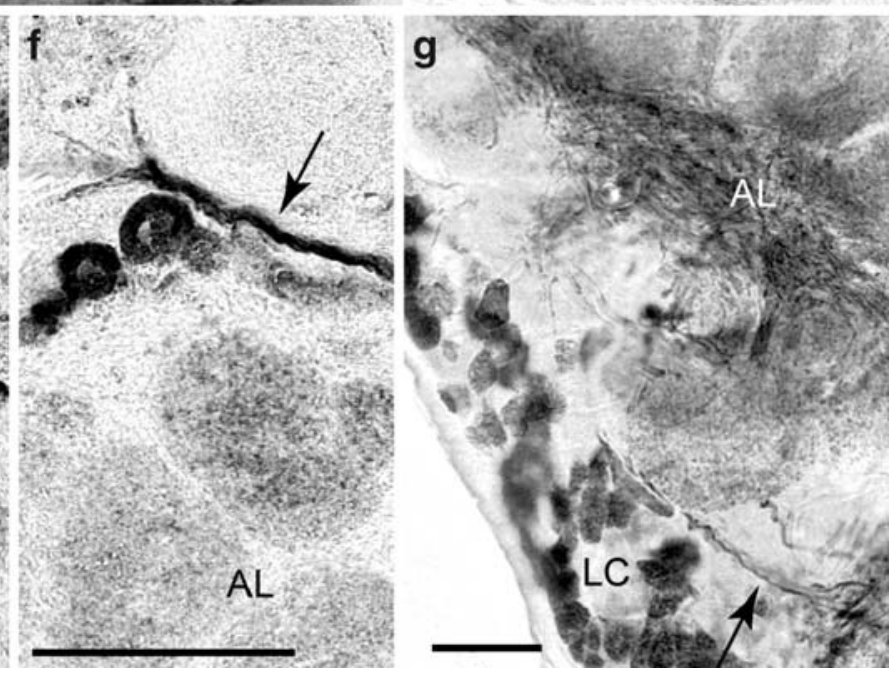

body). c Horizontal section showing a loose bundle of stained fibers leaving the ventral part of the antennal lobe via the outer antennocerebral tract (arrow). d-f Three adjacent horizontal sections, from ventral (d) to dorsal (f), showing stained fibers in the dorsal antennocerebral tract (arrows). g Frontal section through the antennal lobe $(A L)$. Several immunostained fibers (arrow) connect the antennal lobe with the antennal mechanosensory and motor center and/or the subesophageal ganglion ( $L C$ lateral cell cluster). Bars $50 \mu \mathrm{m}$ 

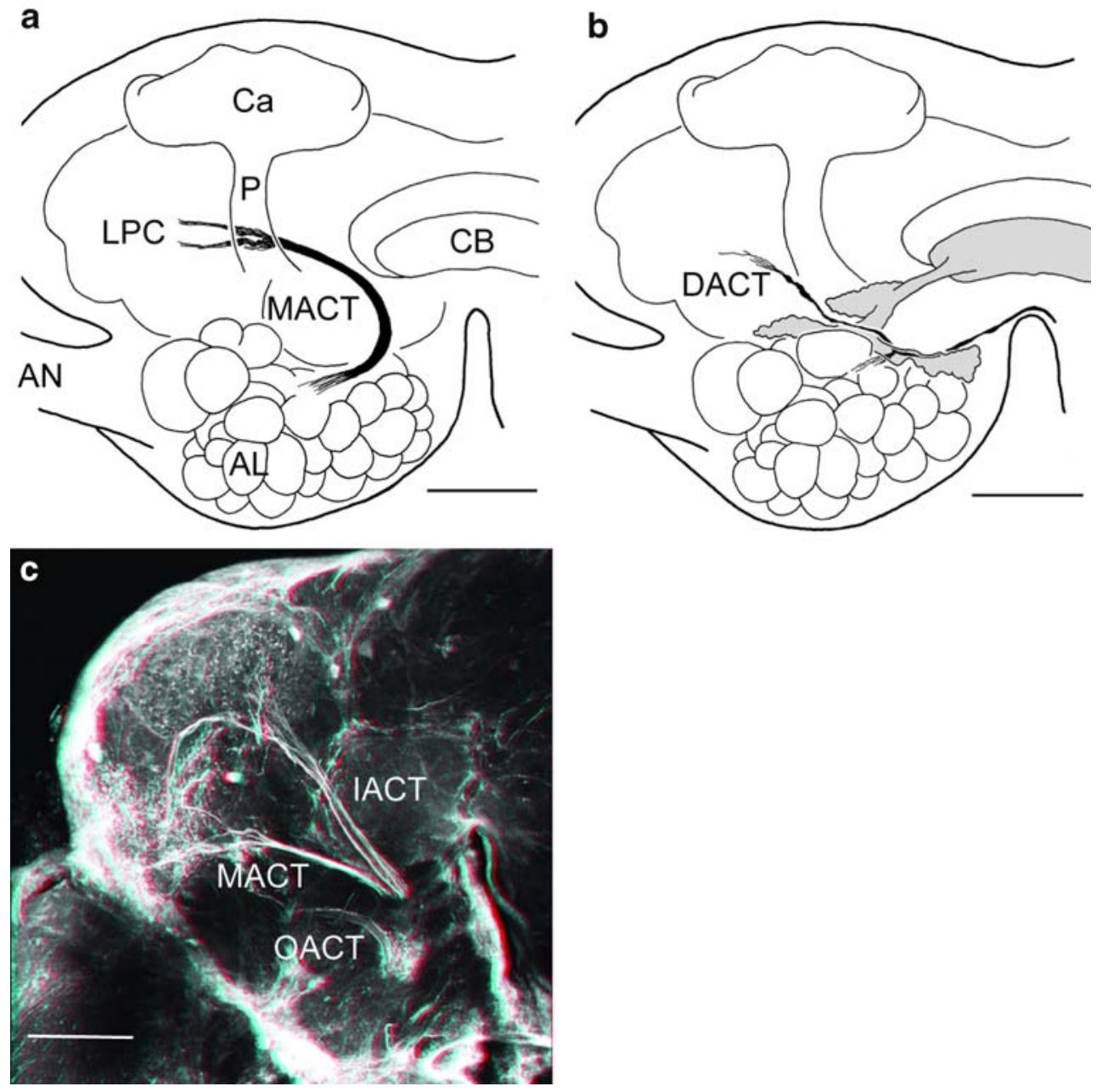

Fig. 3 GABA immunostaining in antennocerebral tracts. a, b Reconstructions originating from the preparation shown in Fig. 1a ( $C a$ calyces, $P$ pedunculus, $C B$ central body, $L P C$ lateral protocerebrum, $A L$ antennal lobe, $A N$ antennal nerve). a Camera lucida reconstruction of GABA-immunolabeled axons in the middle antennocerebral tract $(M A C T)$. b Reconstruction of GABA-immunolabeled axons in the dorsal antennocerebral tract $(D A C T)$. The stained axons project medially from the antennal lobe and pass around primary neurites of GABA-immunoreactive tangential neurons of the lower division of the central body (shaded area). One sub-bundle of fibers

investigating the stained somata in the lateral cell cluster for double-immunofluorescence. The LomTK II antiserum revealed a mean of five immunostained cell bodies $(n=6$, $\mathrm{SD}=1)$, none of which were GABA-immunoreactive $(n=6$, $\mathrm{SD}=0$; Fig. 4a). Likewise, LomTK II immunostaining was not colocalized with GABA immunostaining in the glomerular neuropil (Fig. 4b). In a previous study, Berg et al. (2007) estimated there being about 64 FMRFamide-, 87 Mas-AT-, and 47 Dip-Ast7-immunoreactive cells in the lateral cell cluster. The large majority of these cells showed colocalization of peptide and GABA immunoreactivities (Fig. 5). Only a few cell bodies stained by the three neuropeptide antisera were not GABA-immunolabeled. These included a single

makes a sharp turn and projects dorso-laterally along the lower part of the pedunculus, whereas another branch joins a commissure connecting to the contralateral brain hemisphere. c For comparison, the three main protocerebral tracts, viz., the inner $(I A C T)$, middle $(M A C T)$, and outer $(O A C T)$ antennocerebral tracts are shown in a stereoscopic image (use red/green spectacles for three-dimensional viewing, with the green lens in front of the left eye). The confocal reconstruction originates from a preparation retrogradely labeled by applying fluorescent dye into the antennal lobe. The dorsal antennocerebral tract is not visible. Bars $50 \mu \mathrm{m}$

large Ast-A-labeled cell body (Fig. 6a), one large Mas-ATlabeled cell body (Fig. 6b), and one large FMRFamidelabeled cell body (Fig. 6c), all located ventrally in the lateral cell cluster.

\section{Discussion}

GABA: main inhibitory transmitter of antennal lobe

The results presented here suggest the widespread occurrence of GABA in the antennal lobe of $H$. virescens. The dense immunostaining throughout all the glomeruli supports an 

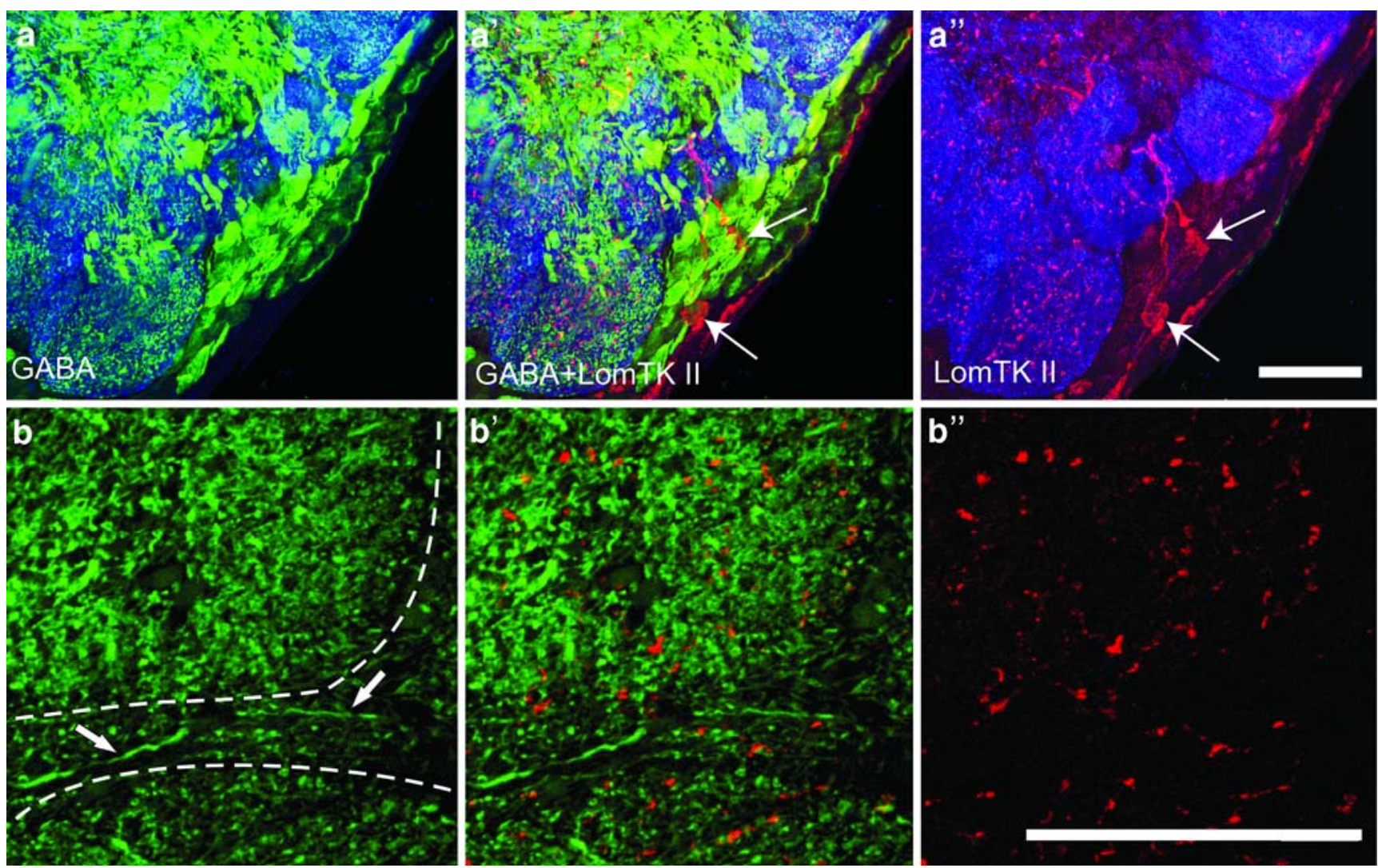

Fig. 4 Confocal images from stacks of 8-10 optical sections showing double-immunofluorescence of GABA- and LomTK II immunostaining. Left, right Images obtained at different excitation wavelengths. Middle Overlay. a-a" Immunolabeling of GABA (green) and LomTK II (red) shows somata immunoreactive for each antiserum (a, a"), but no double-labeled somata (a'). Note two somata and primary neurites immunoreactive for LomTK II but not for GABA (arrows in a', a").
Immunolabeling of synapsin (blue) shows the neuropil structures. b-b" Images showing glomerular neuropil at high magnification. LomTK-IIimmunoreactive profiles (red, b") are, by displaying a pattern of granular staining throughout the glomerulus, considerably different from the GABA-immunoreactive profiles (green, b). Glomerular boundaries are indicated by dashed lines (arrows GABA-immunoreactive fibers running between the two glomeruli). Bars $50 \mu \mathrm{m}$ important role of GABA in processing general olfactory information, including signals from pheromones, interspecifically acting substances, and plant odors. Berg et al. (2007) have shown that neuropeptides related to Mas-AT, Dip-Ast7, and FMRFamide are largely present in local interneurons of the antennal lobe of $H$. virescens. The colocalization of these peptides and GABA in a large number of cell bodies in the lateral cell cluster therefore indicates that many GABA-immunoreactive neurons are local neurons. This is in full agreement with previous reports in the sphinx moth $M$. sexta and several other insect species (Hoskins et al. 1986; Homberg et al. 1989; for reviews, see Homberg and Müller 1999; Utz et al. 2008). The inhibitory effect of GABA was demonstrated for the moth antennal lobe more than 20 years ago (Waldrop et al. 1987). Data from several insects, including $M$. sexta, have subsequently revealed that GABA synchronizes firing patterns in groups of antennal-lobe output neurons (MacLeod and Laurent 1996; Lei et al. 2002). Two GABA-gated conductances with different kinetics have been reported in the antennal lobe of
Drosophila melanogaster: a fast conductance induced by the activation of an ionotropic receptor $\left(\mathrm{GABA}_{\mathrm{A}}\right.$ type) and a slower conductance induced by the activation of a metabotropic receptor $\left(\mathrm{GABA}_{\mathrm{B}}\right.$ type; Wilson and Laurent 2005). The fast type acts at the beginning of the response and is suggested to synchronize the firing of projection neurons, whereas the slower type acts at a later phase and is proposed to influence the spatio-temporal response pattern of the neurons. A recent publication suggests that GABA mediates presynaptic inhibition by providing, via ionotropic and metabotropic receptors, a gain control that regulates the input information in proportion to the dynamic range of antennal-lobe projection neurons (Olsen and Wilson 2008). Root et al. (2008) have reported that presynaptic gain control varies between distinct input channels based on the different expression levels of $\mathrm{GABA}_{\mathrm{B}}$ receptors. In the olfactory bulb of vertebrates, a corresponding principle of gain control has been demonstrated by presynaptic inhibition via periglomerular cells releasing GABA onto axodendritic synapses (Vučinié et al. 2006; Nawroth et al. 2007). 

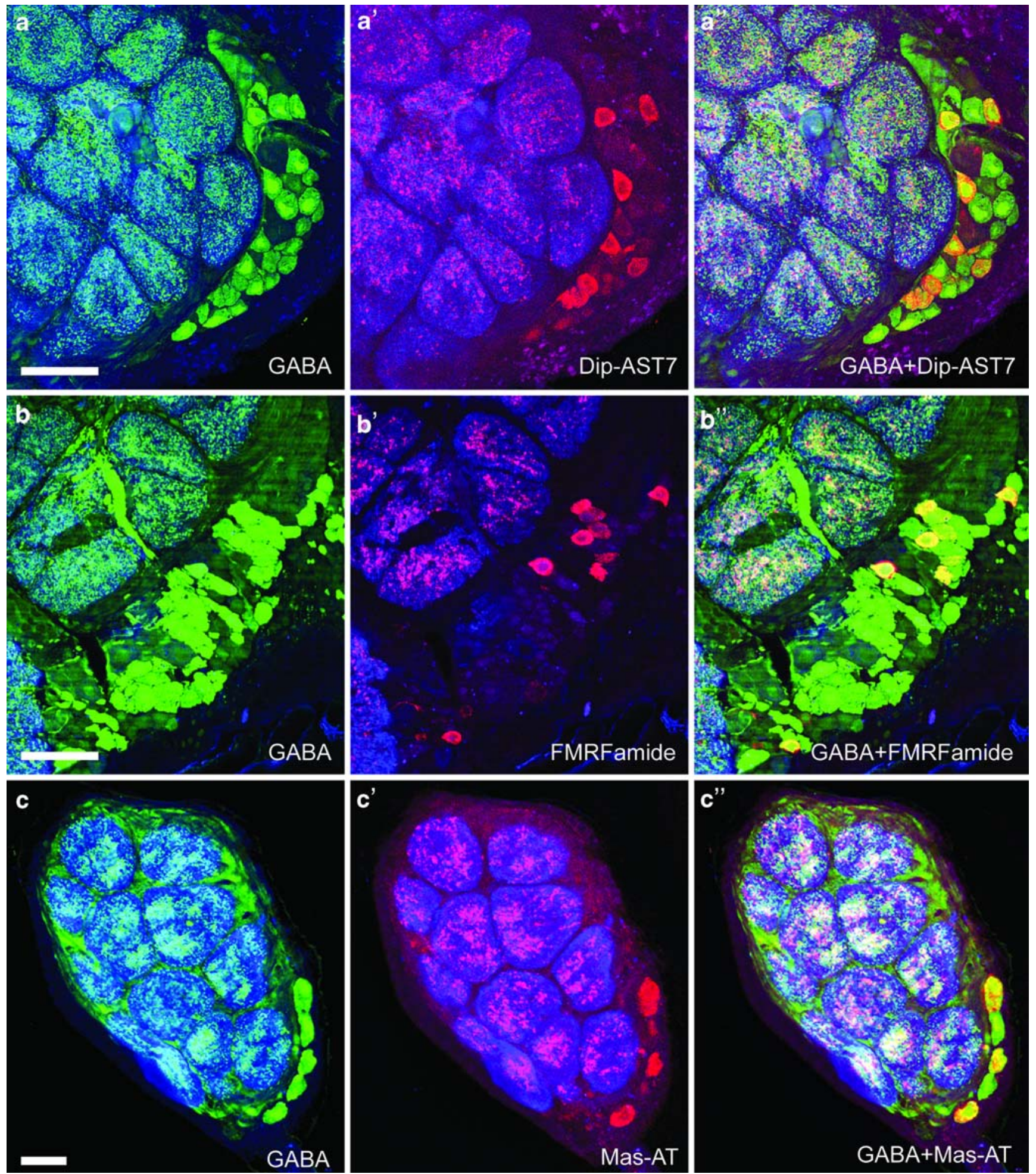

Fig. 5 Confocal images from stacks of $8-10$ optical sections showing double-immunofluorescent staining for GABA in combination with one of three neuropeptides, viz., Dip-AST7, FMRFamide, and MasAT. Left, middle Images obtained at different excitation wavelengths. Right Overlay. Anti-synapsin staining is shown in blue. a-a" Immunolabeling for GABA (green) and Dip-AST7 (red) shows somata immunoreactive for each antiserum (a, a'), and the total colocalization (orange) of Dip-AST7 immunostaining with GABA immunolabeling (a"). b-b" Immunolabeling for GABA (green) and FMRFamide (red) shows somata immunoreactive for each antiserum $\left(\mathbf{b}, \mathbf{b}^{\prime}\right)$ and the colocalization (yellow) of GABA immunoreactivity in all FMRFamide-immunostained somata (b"). c-c" Immunolabeling for GABA (green) and Mas-AT (red) shows somata immunoreactive for each antiserum (c, c') and colocalization (yellow/orange) of GABA immunostaining in all Mas-AT-immunoreactive somata (c"). Bars $50 \mu \mathrm{m}$ 

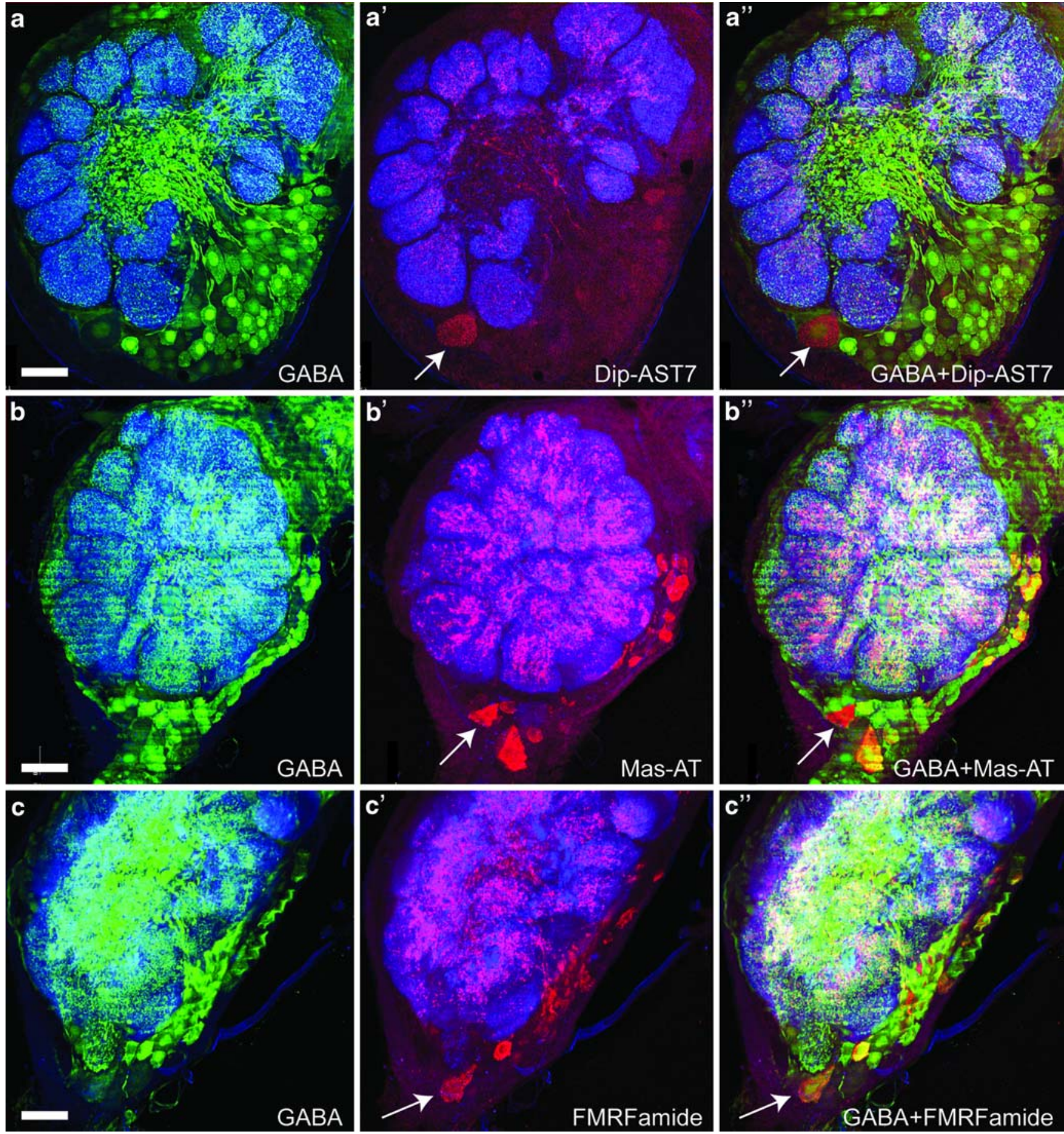

Fig. 6 Confocal images from stacks of 8-10 optical sections showing double-immunofluorescent staining for GABA in combination with various neuropeptides. Left, middle Images obtained at different excitation wavelengths. Right Overlay. Synapsin immunostaining (blue) shows neuropil structures. a-a" Immunolabeling for GABA (green) and Dip-AST7 (red). Note the single Dip-AST7-immunoreactive soma that

GABA in antennocerebral tracts

Prominent staining of fibers in the MACT suggests that a substantial proportion of antennal-lobe projection neurons, lacks GABA immunostaining (arrows in a', a"). b-b" Immunolabeling for GABA (green) and Mas-AT (red). A single large Mas-ATimmunostained soma does not show GABA immunoreactivity (arrows in b', b"). c-c" Immunolabeling for GABA (green) and FMRFamide (red). A single large FMRFamide-immunolabeled soma (arrows in $\mathbf{c}^{\prime}$, c") does not exhibit GABA immunoreactivity. Bars $50 \mu \mathrm{m}$

which target the lateral protocerebrum directly, is GABAergic. Because of dense fasciculation, the numbers of immunostained fibers have not been calculated but, as judged by the thickness of the immunostained fiber bundle, 
may be in the range of $40-70$ fibers. These neurons are probably multiglomerular projection neurons since intracellular recordings from the antennal lobe of $H$. virescens have shown consistently that axons passing in the MACT arborize in several glomeruli ( $\mathrm{R} \varnothing$ et al. 2006). A corresponding subpopulation of GABA-immunoreactive projection neurons has previously been identified in $M$. sexta (Hoskins et al. 1986; Homberg et al. 1989). In honeybees, the presence of GABA-immunoreactive fibers in a tract projecting directly to the lateral protocerebrum (the so-called mediolateral antennoglomerular tract) has also been reported (Schäfer and Bicker 1986). Labeled axons in the dorsal antennocerebral tract, estimated roughly as being 10-20 fibers, may include projection neurons targeting the contralateral hemisphere, analagous to previous findings in the sphinx moth (Homberg et al. 1989). The functional role of GABA in these projections neurons is not known, but the release of GABA probably leads to an odor-dependent inhibition of target brain areas. Some MACT neurons project, like other antennal-lobe projection neurons, to the lateral horn of the protocerebrum (Rø et al. 2006). GABAergic inhibitory input from the MACT might therefore converge in this brain area with excitatory input from the inner and outer antennocerebral tracts. This might further enhance odor discrimination and sensitivity. MACT neurons with wide projections in the protocerebrum might selectively shift attention in target areas through odordependent inhibition.

Co-localization of GABA and neuropeptides related to AST-A, Mas-AT, and FMRFamide

In contrast to LomTK-II-related peptides, which are present in a unique population of somata, neuropeptides related to AST-As, Mas-AT, and FMRFamide largely colocalize with GABA. As illustrated in Fig. 6, three large somata show immunoreactivity exclusively for one of the neuropeptides. This indicates that AST-As, Mas-AT, and FaRPs mainly act as co-transmitters within an inhibitory neural network of the antennal lobe. The combination of GABA and neuropeptides generates additional biochemical heterogeneity within the population of local interneurons. This heterogeneity is even more pronounced as subpopulations of the AST-A-, Mas-AT-, and FaRP-immunoreactive local interneurons contain at least a second neuropeptide (Berg et al. 2007). Mass spectrometry, furthermore, suggests that up to 50 different peptides may be present in the antennal lobe of H. virescens (Berg et al. 2007). Typically, neuropeptides are ligands of G-protein-coupled receptors that indirectly modulate a variety of ion channels in target cells (for a review, see Nässel 2002). Such modulation can change the intrinsic properties of a given neuron and the synaptic strength between neurons, resulting in changing properties of a neuronal network as demonstrated in the crustacean stomatogastric nervous system (Nusbaum et al. 2001; Marder and Tirumalai 2002; Marder and Bucher 2007). The variety of neuropeptides present in sets of local neurons of the antennal lobe may allow for the binding and synchronization of groups of antennal-lobe projection neurons encoding a particular odor mixture. The testing of this idea or alternative hypotheses regarding the contribution of neuropeptides together with GABA in the shaping of olfactory responses of projection neurons will be a challenge for future research.

\section{Comparison with other moth species}

The results presented here are largely in accordance with previous findings in $M$. sexta. In both species, GABA-labeled somata are located exclusively in the lateral cell cluster (Hoskins et al. 1986). A distinction between two spatially different sub-populations of somata, however, as described in $M$. sexta, has not been found in $H$. virescens. The general staining patterns in the antennocerebral tracts show striking similarities. In both species, the inner tract is largely free of immunostained fibers, whereas the middle tract displays pronounced immunoreactivity. Our findings of stained fibers in the outer and the dorsal tract and of a few labeled axons passing to the antennal mechanosensory and motor center or subesophageal ganglion are in full agreement with data obtained in M. sexta (Hoskins et al. 1986). Moreover, the observation of a few large cell bodies located ventrally in the lateral cell cluster, stained by neuropeptide antisera only, is in accordance with previous findings. In M. sexta, two large somata with positions similar to those in $H$. virescens have been labeled with antisera against Mas-AT and FMRFamide but are devoid of GABA immunoreactivity. They have been assigned as somata of projection neurons sending their axons to the tritocerebrum and probably the subesophageal ganglion (Schachtner et al. 2004; Utz et al. 2008).

\section{Non-GABAergic local neurons}

Our double-labeling experiments have shown that none of the LomTK-II-immunoreactive somata are GABAimmunoreactive. Since tachykinin-related peptides have previously been demonstrated as being present exclusively in local antennal-lobe neurons and not in projection neurons (Berg et al. 2007), the lack of colocalization with GABA demonstrates the existence of local interneurons that utilize a transmitter substance different from GABA. Behavioral tests in fruit flies have reported reduced olfactory sensitivity in animals lacking TKRPs (Winther et al. 2006). 
Recently, the presence of excitatory cholinergic local neurons has been discovered in the antennal lobe of the fruit fly (Shang et al. 2007). These neurons are suggested to act as a general enhancer to guarantee the reliable transmission of olfactory information to the Kenyon cells of the mushroom bodies. Furthermore, a subpopulation of GABA-immunonegative local neurons has been identified in the antennal lobe of the silk moth, Bombyx mori (Seki and Kanzaki 2008). Interestingly, the LomTK-IIimmunoreactive somata reported here are slightly larger than the other local neurons (Berg et al. 2007), a finding that also applies to the somata of the cholinergic local neurons in the fly (Shang et al. 2007). Whether the few non-GABAergic neurons revealed in these three species constitute corresponding populations remains to be seen.

Acknowledgments We thank Drs. T. G. Kingan, H. Agricola, E. Buchner, J. Veenstra, and E. Marder for providing antisera. We are also grateful to Martina Kern for technical assistance and to Syngenta, Basel, Switzerland for sending pupae.

Open Access This article is distributed under the terms of the Creative Commons Attribution Noncommercial License which permits any noncommercial use, distribution, and reproduction in any medium, provided the original author(s) and source are credited.

\section{References}

Abercrombie M (1946) Estimation of nuclear population from microtome sections. Anat Rec 94:239-247

Almaas TJ, Mustaparta H (1991) Heliothis virescens: response characteristics of receptor neurons in sensilla trichodea type 1 and type 2. J Chem Ecol 5:953-972

Anton S, Homberg U (1999) Antennal lobe structure. In: Hansson BS (ed) Insect olfaction. Springer, Berlin Heidelberg New York, pp 97-124

Berg BG, Tumlinson JH, Mustaparta H (1995) Chemical communication in heliothine moths. IV. Receptor neuron responses to pheromone compounds and formate analogues in the male tobacco budworm moth Heliothis virescens. J Comp Physiol [A] 177:527-534

Berg BG, Almaas TJ, Bjaalie JG, Mustaparta H (1998) The macroglomerular complex of the antennal lobe in the tobacco budworm moth Heliothis virescens: specified subdivision in four compartments according to information about biologically significant compounds. J Comp Physiol [A] 183:669-682

Berg BG, Galizia CG, Brandt R, Mustaparta H (2002) Digital atlases of the antennal lobe in two species of tobacco budworm moths, the oriental Helicoverpa assulta (male) and the American Heliothis virescens (male and female). J Comp Neurol 446:123-134

Berg BG, Schachtner J, Utz S, Homberg U (2007) Distribution of neuropeptides in the primary olfactory center of the heliothine moth Heliothis virescens. Cell Tissue Res 327:385-398

Boeckh J, Tolbert LJ (1993) Synaptic organization and development of the antennal lobe in insects. Microsc Res Tech 24:260-280

Boer HH, Schot LP, Roubos EW, Maat A ter, Lodder JC, Reichelt D, Swaab DF (1979) ACTH-like immunoreactivity in two electronically coupled giant neurons in the pond snail Lymnaea stagnalis. Cell Tissue Res 202:231-240
Christensen TA, Mustaparta H, Hildebrand JG (1995) Chemical communication in heliothine moths. VI. Parallel pathways for information processing in the macroglomerular complex of the male tobacco budworm moth Heliothis virescens. J Comp Physiol [A] 177:545-557

Distler P (1989) Histochemical demonstration of GABA-like immunoreactivity in cobalt labeled neuron individuals in the insect olfactory pathway. Histochemistry 91:245-249

Hansson BS, Almaas TJ, Anton S (1995) Chemical communication in heliothine moths. V. Antennal lobe projection patterns of pheromone-detecting olfactory receptor neurons in the male Heliothis virescens (Lepidoptera: Noctuidae). J Comp Physiol [A] 177:535-543

Hildebrand JG, Shepherd GM (1997) Mechanisms of olfactory discrimination: convergent evidence for common principles across phyla. Annu Rev Neurosci 20:595-611

Homberg U, Montague RA, Hildebrand JG (1988) Anatomy of antenno-cerebral pathways in the brain of the sphinx moth Manduca sexta. Cell Tissue Res 254:255-281

Homberg U, Christensen TA, Hildebrand JG (1989) Structure and function of the deutocerebrum in insects. Annu Rev Entomol 34:477-501

Homberg U, Müller U (1999) Neuroactive substances in the antennal lobe. In: Hansson BS (ed) Insect olfaction. Springer, Berlin Heidelberg New York, pp 181-206

Hoskins SG, Homberg U, Kingan TG, Christensen TA, Hildebrand JG (1986) Immunocytochemistry of GABA in the antennal lobes of the sphinx moth Manduca sexta. Cell Tissue Res 244:243-252

Laurent G (2002) Olfactory network dynamics and the coding of multidimensional signals. Nat Rev Neurosci 3:884-895

Lei H, Christensen TA, Hildebrand JG (2002) Spatial and temporal organization of ensemble representations for different odor classes in the moth antennal lobe. J Neurosci 24:11108-11119

Leitch B, Laurent G (1996) GABAergic synapses in the antennal lobe and mushroom body of the locust olfactory system. J Comp Neurol 372:487-514

MacLeod K, Laurent G (1996) Distinct mechanisms for synchronization and temporal patterning of odor-encoding neural assemblies. Science 274:976-979

Marder E, Bucher D (2007) Understanding circuit dynamics using the stomatogastric nervous system of lobsters and crabs. Annu Rev Physiol 69:291-316

Marder E, Tirumalai V (2002) Cellular, synaptic and network effects of neuromodulation. Neural Networks 15:479-493

Marder E, Calabrese RL, Nusbaum MP, Trimmer B (1987) Distribution and partial characterization of FMRFamide-like peptides in the stomatogastric nervous system of the rock crab, Cancer borealis, and the spiny lobster Panulirus interruptus. J Comp Neurol 259:150-163

Möhler H (2006) $\mathrm{GABA}_{\mathrm{A}}$ receptor diversity and pharmacology. Cell Tissue Res 326:505-516

Nässel DR (2002) Neuropeptides in the nervous system of Drosophila and other insects: multiple roles as neuromodulators and neurohormones. Prog Neurobiol 68:1-84

Nässel DR, Kim M-Y, Lundquist CT (1995) Several forms of callytachykinins are distributed in the central nervous system and intestine of the blowfly Calliphora vomitoria. J Exp Biol 198:2527-2536

Nawroth JC, Greer AG, Chen WR, Laughlin SB, Sheperd GM (2007) An energy budget for the olfactory glomerulus. J Neurosci 27:9790-9800

Negoescu A, Labat-Moleur F, Lorimier P, Lamarcq L, Guillermet C, Chambaz E, Brambilla E (1994) F(ab) secondary antibodies: a general method for double immunolabeling with primary antisera from the same species. Efficiency control by chemoluminescence. J Histochem Cytochem 42:433-437 
Nusbaum MP, Blitz DM, Swensen AM, Wood D, Marder E (2001) The roles of co-transmission in neural network modulation. Trends Neurosci 24:146-154

Olsen SR, Wilson RI (2008) Lateral presynaptic inhibition mediates gain control in an olfactory circuit. Nature 452:956-960

Root CM, Masuyama K, Green DS, Enell LE, Nässel DR, Lee C-H, Wang JW (2008) A presynaptic gain control mechanism finetunes olfactory behavior. Neuron 59:311-321

Rø H, Müller D, Mustaparta H (2006) Anatomical characterization of antennal lobe projection neurons. J Comp Neurol 500:658-675

Salio S, Lossi L, Ferrini F, Merighi A (2006) Neuropeptides as synaptic transmitters. Cell Tissue Res 326:583-598

Schachtner J, Trosowski B, D’Hanis W, Stubner S, Homberg U (2004) Development and steroid regulation of RFamide immunoreactivity in antennal lobe neurons of the sphinx moth Manduca sexta. J Exp Biol 207:2389-2400

Schachtner J, Schmidt M, Homberg U (2005) Organization and evolutionary trends of primary olfactory brain centers in Tetraconata (Crustacea + Hexapoda). Arthropod Struct Devel 34:257-299

Schäfer S, Bicker G (1986) Distribution of GABA-like immunoreactivity in the brain of the honeybee. J Comp Neurol 246:287-300

Seki Y, Kanzaki R (2008) Comprehensive morphological identification and GABA immunocytochemistry of antennal lobe local interneurons in Bombyx mori. J Comp Neurol 506:93-107

Shang Y, Claridge-Chang A, Sjulson L, Pypaert M, Miesenböck G (2007) Excitatory local circuits and their implications for olfactory processing in the fly antennal lobe. Cell 128:601-612

Shepherd GM (1974) The synaptic organization of the brain. An introduction. Oxford University Press, New York

Sternberger LA (1979) Immunocytochemistry. Wiley, New York

Stranden M, Røstelien T, Liblikas I, Almaas TJ, Borg-Karlson A-K, Mustaparta H (2003) Receptor neurons in three heliothine moths responding to floral and inducible plant volatiles. Chemoecology $13: 143-154$
Utz S, Huetteroth W, Vömel M, Schachtner J (2008) Mas-allatotropin in the developing antennal lobe of the sphinx moth Manduca sexta: distribution, time course, developmental regulation and colocalization with other neuropeptides. Dev Neurobiol 68:123-142

Veenstra JA, Hagedorn HH (1993) Sensitive enzyme immunoassay for Manduca allatotropin and the existence of an allatotropinimmunoreactive peptide in Periplaneta americana. Arch Insect Biochem Physiol 23:99-109

Vickers NJ, Christensen TA (2003) Functional divergence of spatially conserved olfactory glomeruli in two related moth species. Chem Senses 28:325-338

Vickers NJ, Christensen TA, Hildebrand JG (1998) Combinatorial odor discrimination in the brain: attractive and antagonist odor blends are represented in distinct combinations of uniquely identifiable glomeruli. J Comp Neurol 400:35-56

Vitzthum H, Homberg U, Agricola H (1996) Distribution of Dipallatostatin I-like immunoreactivity in the brain of the locust Schistocerca gregaria with detailed analysis of immunostaining in the central complex. J Comp Neurol 369:419-437

Vučinié D, Lawrence B, Cohen B, Kosmidis EK (2006) Interglomerular center-surround inhibition shapes odorant-evoked input to the mouse olfactory bulb in vivo. J Neurosci 95:1881-1887

Waldrop B, Christensen TA, Hildebrand JG (1987) GABA-mediated synaptic inhibition of projection neurons in the antennal lobe of the sphinx moth, Manduca sexta. J Comp Physiol [A] 61:23-32

Weevers RD (1966) A lepidopteran saline: the effects of inorganic cation concentrations on sensory reflex and motor responses in a herbivorous insect. J Exp Biol 44:163-176

Wilson RI, Laurent G (2005) Role of GABA inhibition in shaping odor-evoked spatiotemporal patterns in the Drosophila antennal lobe. J Neurosci 25:9069-9079

Winther ÅM, Acebes A, Ferrús A (2006) Tachykinin-related peptides modulate odor perception and locomotor activity in Drosophila. Mol Cell Neurosci 31:399-406 